\title{
Recent Stratospheric Temperature Observed from Satellite Measurements
}

\author{
Quanhua Liu ${ }^{1}$ and Fuzhong Weng ${ }^{2}$ \\ ${ }^{1} J o i n t$ Center for Satellite Data Assimilation, Camp Springs, Maryland, USA \\ ${ }^{2} N O A A / N E S D I S / S T A R$, Camp Springs, Maryland, USA
}

\begin{abstract}
Some important recent findings in climate studies are the warming trend in the troposphere and the cooling trend in the stratosphere. However, the evidence for the cooling trend in the stratosphere may need to be revisited. This study presents evidence that the stratosphere is slightly warming since 1996. Using long-term Stratosphere Sounding Unit (SSU) measurements at channels 1 and 2 before 1996, we did obtain a cooling trend in the middle and upper parts of stratosphere similar to the findings for the lower stratosphere in literature (Ramaswamy et al. 2001; Fu et al. 2004). But, we also found that the temperature trend in the middle and upper stratosphere has alternated to warming since 1996. We also analyzed a time series of the Microwave Sounding Unit (MSU) channel 4 brightness temperatures between 1978 and 2006 and found the same reversing trend in the lower stratosphere. The reversing trend may relate to a possible recovery of stratospheric ozone concentration.
\end{abstract}

\section{Introduction}

The temperature in the lower and middle stratosphere is critical for forming polar stratospheric clouds, and is a key environmental factor during chemical ozone loss. The global-mean stratospheric temperature change has traditionally represented an important diagnostic for ozone depletion (Shepherd and Jonsson 2007). The cooling trend in the stratosphere was evaluated using the Microwave Sounding Unit (MSU) channel 4 which measures the lower part of the stratosphere (Ramaswamy et al. 2001; Fu et al. 2004).

Stratospheric temperatures depend on stratospheric dynamics, radiation, and composition. Solar cycle and quasi-biennial oscillation (QBD) may also affect stratospheric temperature. In this paper, we analyze long-term MSU and SSU measurements and provide evidence for a stratospheric temperature warming since 1996. Section 2 of this paper described the satellite data. The radiative transfer model for the SSU simulation is given in Section 3. Consistency adjustment between satellites is addressed in Section 4. The trend in the stratospheric temperature is explained in Section 5. The last section is for discussions.

\section{Data}

The data used in this study are from the MSU and SSU sensors onboard NOAA satellite missions. The first MSU and SSU mission was started onboard TIROS-N in October 1978. The mission was ended onboard NOAA-

Corresponding author: Quanhua Liu, Joint Center for Satellite Data Assimilation, Camp Springs, Maryland 20746, USA. Email: Quanhua.Liu@noaa.gov. @2009, the Meteorological Society of Japan.

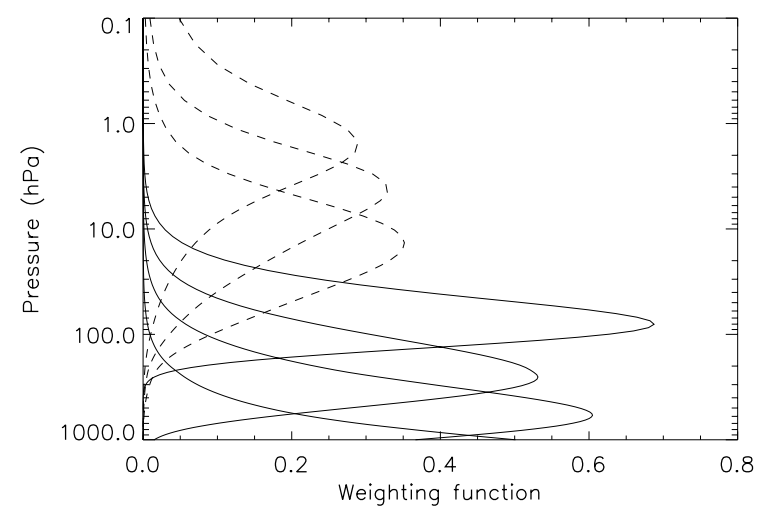

Fig. 1. SSU weighting functions (dashed lines) and MSU weighting functions (solid lines). The US 1976 standard atmospheric profile is used. The weighting function is a derivative of transmittance to optical depth. The peak of the weighting function generally indicates a main contribution place to satellite signature.

14 in 2007. The four MSU channels measure the Earth's surface, lower troposphere, middle troposphere, and lower stratosphere, respectively (see solid lines for their weighting functions in Fig. 1). The MSU data have widely been used in studying the trend in the lower troposphere (Spencer and Christy 1990; Vinnikov and Grody 2003) and the lower stratosphere (Ramaswamy et al. 2001; Fu et al. 2004). In this study, a longer time series of the MSU channel 4 brightness temperatures at nadir is used in studying the lower stratospheric temperature. The SSU data are rarely applied due to its complicated sensor response and the leaking problem in the $\mathrm{CO}_{2}$ cell pressure modulator. We apply a line-by-line transmittance model to generate the sensor response function for a fast transmittance model, and we use the Community Radiative Transfer Model (CRTM) (Weng 2007; Liu and Weng 2006), developed at the Joint Center for Satellite Data Assimilation in the United States, to quantitatively correct the leaking effect.

The SSU onboard the series of NOAA polar-orbiting satellites provides unique 29-year observations for studying stratospheric temperatures. The SSU is a stepscanned infrared spectrometer employing a selective absorption technique to make measurements at the top of the Earth's atmosphere in three channels in the 15 micron carbon dioxide absorption band. The three SSU channels have the same frequency but different $\mathrm{CO}_{2}$ cell pressures. With the three modulated cell pressures, the weighting function of the original 15 micron carbon dioxide absorption band is shifted up and split into three weighting functions, approximately located at 15 , 5 , and $1.5 \mathrm{hPa}$. The three SSU channels measure middle stratosphere, upper stratosphere, and upper stratosphere and lower mesosphere, respectively (see dashed lines for the weighting functions in Fig. 1). 


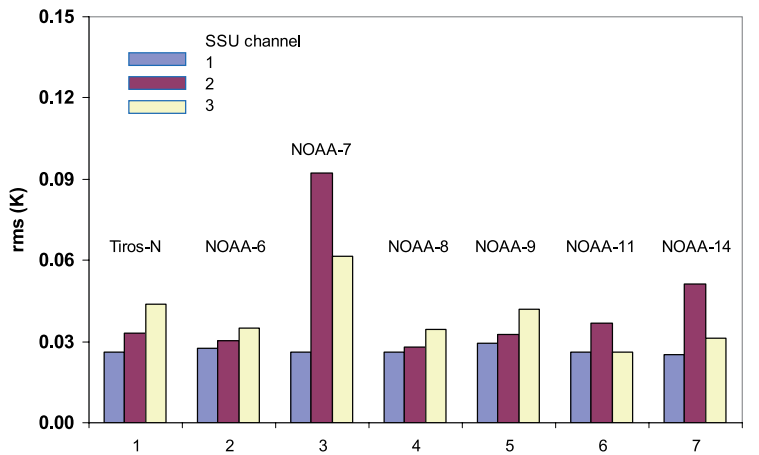

Fig. 2. SSU brightness temperature fitting root mean square error in the CRTM simulation. The fitting error is composed of a fitting error in atmospheric absorption and an interpolation error for $\mathrm{CO}_{2}$ cell pressure of the instrument.

\section{Extension of the CRTM for SSU}

In order to take account for the effect of $\mathrm{CO}_{2}$ cell pressure leaking on the SSU sensor response, the transmittance model in the CRTM uses a set of coefficients depending on the $\mathrm{CO}_{2}$ cell pressures to compute atmospheric transmittances. By comparison to the detailed line-by-line calculation, the rms error due to the fitting and interpolation of the $\mathrm{CO}_{2}$ cell pressure in the fast transmittance model is less than $0.1 \mathrm{~K}$ (see Fig. 2). We also validate the SSU radiative transfer calculations against the SSU measurements. The input temperature profiles are taken from the Earth Observing System (EOS) Aura microwave limb sounding (MLS) product for November 2004, a completely independent data source. More than 7000 match-up data points are found, and all the data points are analyzed. Figures $3 \mathrm{a}$ and $3 \mathrm{~b}$ show that the radiative transfer calculation is very accurate. The SSU and the MLS measurements are very consistent. The bias and standard deviation in the brightness temperature calculations at the SSU channels 1 and 2 are less than (or equal to) 1 Kelvin.

\section{Consistency adjustment between satellites}

For climate study, a consistent time series of measurements is extremely important. Intensified intersatellite calibration for the MSU has been performed using an overlapping technique between satellites in the literature (Ramaswamy et al. 2001; Fu et al. 2004). For infrared sensors, the changes in the atmospheric $\mathrm{CO}_{2}$ and sensor response function have to be taken into account. The infrared sensor SSU is more intricate because of the $\mathrm{CO}_{2}$ cell pressure modulator. We choose 110,40 , and $14.5 \mathrm{hPa}$ as the reference $\mathrm{CO}_{2}$ cell pressures for the SSU channels 1,2 , and 3 , respectively.

All SSU brightness temperatures are corrected to the reference cell pressures. In order to represent consistent climate observations, the global monthly mean brightness temperatures between satellites at an overlap month are adjusted to be the same, and the adjustment value is applied to the adjusted sensor over its whole mission time. The adjustment implies that the global mean of the brightness temperature for the same month from adjacent satellites represents the same atmospheric information.

The time series of global mean brightness temperature represents a radiative effective atmospheric temperature. The effective atmospheric temperature depends on sensor characteristics. For a microwave

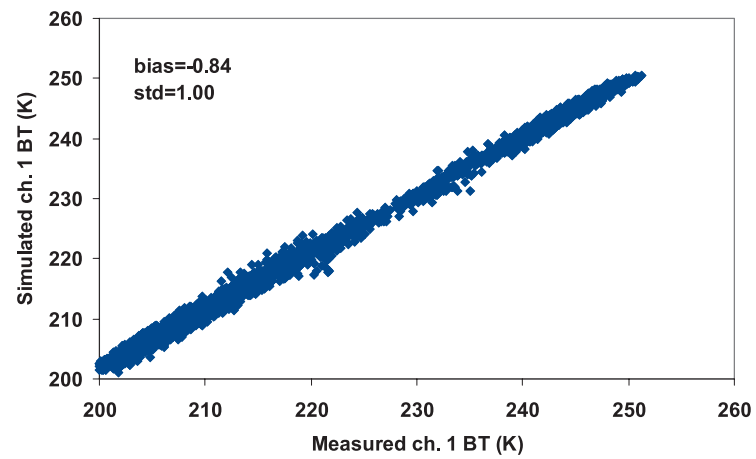

Fig. 3a. Comparisons of the SSU brightness temperature at channel 1 between calculations and measurements for November 2004.

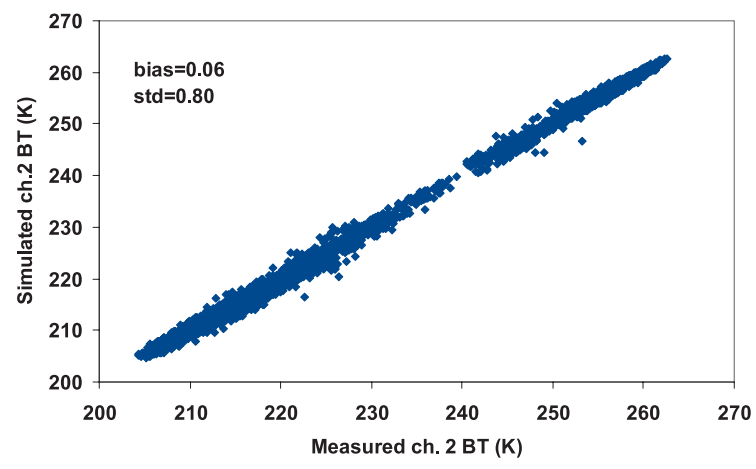

Fig. 3b. Same as Fig. 3a, but for the SSU channel 2.

sensor like MSU, the global mean brightness temperatures at channels 2 and 4 represent the lower troposphere and lower stratospheric temperatures, respectively. For infrared $\mathrm{CO}_{2}$ absorption channels like on SSU, the effective atmospheric temperature depends also on $\mathrm{CO}_{2}$ concentration in the atmosphere, and it may be written as:

$$
B T_{n}(t)=T_{\text {eff }}\left(n, t, \mathrm{CO}_{2}\right),
$$

where $n$ is a channel index for the infrared sensor. The variation of the global mean brightness temperature to time $t$ is defined as:

$$
\frac{d B T_{n}(t)}{d t}=\frac{\partial T_{e f f}\left(n, t, \mathrm{CO}_{2}\right)}{\partial t}+\frac{\partial T_{e f f}\left(n, t, \mathrm{CO}_{2}\right)}{\partial \mathrm{CO}_{2}} \frac{\partial \mathrm{CO}_{2}}{\partial t}
$$

The trend, we are interested in, is the trend in atmospheric temperature, which is:

$$
\begin{aligned}
\text { trend } & =\frac{\partial T_{\text {eff }}\left(n, t, \mathrm{CO}_{2}\right)}{\partial t} \\
& =\frac{d B T_{n}(t)}{d t}-\frac{\partial T_{e f f}\left(n, t, \mathrm{CO}_{2}\right)}{\partial \mathrm{CO}_{2}} \frac{\partial \mathrm{CO}_{2}}{\partial t} .
\end{aligned}
$$

The first term on the right side of Eq. (3) is from the satellite measurement. The second term on the right hand side in Eq. (2) needs to be subtracted. The term involves the derivative of the mean brightness temperature to carbon dioxide amount and the change rate of carbon dioxide amount. The latter is known as the increasing rate of $\mathrm{CO}_{2}$. The carbon dioxide amount has been increased from $336 \mathrm{ppmv}$ in 1978 to $380 \mathrm{ppmv}$ in 2006. Our detailed line-by-line radiative transfer calculations 
show that for a given atmospheric profile the increase of the mean brightness temperature is a linear function of $\mathrm{CO}_{2}$. Fortunately, the increment weakly depends on the structure of the atmospheric profile. The uncertainty of extracting the $\mathrm{CO}_{2}$ effect on the global mean brightness temperature is estimated within $0.02 \mathrm{~K}$. The NOAA polar-orbiting satellites from TIROS-N to NOAA 14 are sun synchronous satellites. Such a satellite normally passes over any given point of the Earth's surface at the same local solar time. Realistically, the NOAA satellite experiences an orbit drift, resulting in a shift in the over pass time. In particular, NOAA-14 had the largest orbit drift, shifting the local over pass time from 2 pm in 1995 to $7 \mathrm{pm}$ in 2006. It is also known that the diurnal variation near the surface and in the stratosphere is significant. The diurnal cycle in temperature near the surface can be up to $3.5 \mathrm{~K}$, then reduces to a small value $(<0.5$ $\mathrm{K}$ ) between 200 and $850 \mathrm{hPa}$, and increases again to 1.5 $\mathrm{K}$ at $10 \mathrm{hPa}$ (Seidel et al. 2005). We may be concerned whether the satellite orbit drift and the diurnal variation in the atmospheric temperature create the reversing trend derived from satellite measurements. Mears et al. (2003) showed that the effect due to the satellite orbit drift and atmospheric diurnal cycle on the trend using MSU channel 2 for the lower troposphere is small. The reason behind this is that the NOAA polar-orbiting satellite passes over a location twice daily in about a 12hour interval between its ascending and descending orbits. The mean value of the ascending and descending measurements minimizes the effect from the orbit drift and the atmospheric diurnal variation. We apply the Community Radiative Transfer Model to quantify this effect on SSU channels 1 and 2. We choose four months of NCEP analysis data in April, July, October 2005, and January 2006. The CRTM is run for the input atmosphere/surface data with the NOAA-14 orbit parameters (time, location, and sensor viewing angles) in 1995 and the orbit parameters in 2005 and 2006. The results show that the change due to the orbit drift in the SSU brightness temperatures at channels 1 and 2 is less than 0.05 K.

\section{Trend of the stratospheric temperature}

As scientists discovered the warming trend in the troposphere (Zou et al. 2006), the cooling trend in the stratosphere was unveiled (Ramaswamy et al. 2001). Fu et al. (2004) showed from the MSU channel 4 measurements that the cooling trend in the stratosphere is much stronger than the warming trend in the troposphere, except for the periods during the El Chichon and Mt. Pinatubo volcano eruptions. However, the information of the MSU channel 4 comes from the lower part of the stratosphere near $70 \mathrm{hPa}$, so the result may not be representative for the entire stratosphere.

In this study, we use the SSU and MSU to study the stratosphere. The MSU channel 4 measures the lower stratospheric temperature while the SSU channels 1 and 2 measure the middle and upper stratospheric temperatures. The SSU channel 3 is not used here since it is sensitive to both the mesosphere and the upper stratosphere. We use a time series of the MSU channel 4 brightness temperatures between 1978 and 2006 to compute the trend in lower stratospheric temperature. We use the MSU sensor onboard NOAA-11 as a reference sensor and adjust the sensors onboard other satellites with overlapping global monthly mean brightness temperatures. The adjustment corrects the discrepancy in the sensors between satellites. One can also use the post-launch simultaneous nadir overpass (SNO) technique to recalibrate the sensor data (Cao et al. 2004). We compute a time series of the anomaly in the MSU channel 4 brightness temperature by subtracting the monthly mean value (see Fig. 4a). For the data before 1996, we obtained a trend of about $-0.51 \pm 0.05 \mathrm{~K}$ per decade, close to the trend in previous studies (Ramaswamy et al. 2001; Fu et al. 2004). The two warming peaks near 1983 and 1992 are the response to volcano outbursts EI Chichon in 1982 and Mt. Pinatubo in 1991, respectively. The latter volcano eruption was much stronger than the former. With 4 years of more data than previous studies, we found that the lower stratospheric temperature is warming since 1996 and the warm trend is $0.22 \pm 0.14 \mathrm{~K}$ per decade with a $95 \%$ confident level.

The SSU data are rarely applied and have not been used in the NCEP data analysis and reanalysis yet. The SSU channel 1 data before 1994 was studied (Brindley et al. 1999) but to our knowledge, the SSU channel 2 data have not been used for climate studies. The study (Brindley et al. 1999) showed a negative trend of the SSU channel 1 brightness temperature. In contrast to the MSU time series of observations, the SSU time series of observations relate to the changes in both atmospheric temperature and $\mathrm{CO}_{2}$ concentration. Even for the same atmospheric temperature profile, the increased $\mathrm{CO}_{2}$ blocks upward radiation and shifts the peak of the weighting function up, resulting in a change in the brightness temperature. In addition, the $\mathrm{SSU}^{\mathrm{CO}} \mathrm{CO}_{2}$ cell leaking needs to be corrected. Fortunately, the SSU signature for atmospheric temperature change is dominant and the increments in the SSU channels 1 and 2 brightness temperatures are quasi-linear function of the increments of $\mathrm{CO}_{2}$ concentration and the $\mathrm{CO}_{2}$ cell pressure for a given atmospheric temperature profile. The effect of the $\mathrm{CO}_{2}$ concentration and the $\mathrm{CO}_{2}$ cell pressure change can be mainly removed from the annual global mean computed by a radiative transfer calculation (Weng 2007; Liu and Weng 2006) for the MLS global data set. The error in this approximation is estimated to be smaller than $0.05 \mathrm{~K}$ for a global annual mean by analyzing the computed brightness temperatures from four months (January, April, July, October in 2005 and January in 2006) of NCEP analysis data. By extracting the $\mathrm{CO}_{2}$ effect, the SSU channel 1 (Fig. 4b) brightness temperature anomaly displays the strong effect from volcano eruptions and the clear cooling trend in the middle stratosphere between 1978 and 1996. We use a linear square fit to compute the trend or slope. An error bar in the trend is obtained at a 95\% confident level. The temperature time series is divided into before 1996 and since 1996 parts based on recent findings in ozone: a negative trend before 1996 and a positive trend since 1996 in the lower stratospheric ozone (Miller et al. 2006). The cooling trend before 1996 in the middle stratosphere is $-1.25 \pm 0.04 \mathrm{~K}$ per decade. The warming trend since 1996 in the middle stratosphere is $0.32 \pm$ $0.05 \mathrm{~K}$ per decade. The cooling trend for the SSU channel 2 (see Fig. 4c) before 1996 is $-0.28 \pm 0.05 \mathrm{~K}$ per decade. The warming trend for the SSU channel 2 since 1996 is $0.78 \pm 0.08 \mathrm{~K}$ per decade, implying a strong warming in the upper stratosphere.

The cooling trend in the lower and middle stratosphere before 1996 may be understood as resulting from ozone loss. Reduction of ozone concentration in the stratosphere decreases radiation absorption, causing a radiative cooling there. Previous study (see http:// www.epa.gov/air/airtrends/aqtrnd96/brochure/stratoz. html) showed clear negative trend in the stratospheric ozone before 1996. Newchurch et al. (2000) found the negative ozone trend in the upper stratosphere by analyzing ground and satellite measurements between 1979 and 1998. Therefore, the cooling trend in the lower 

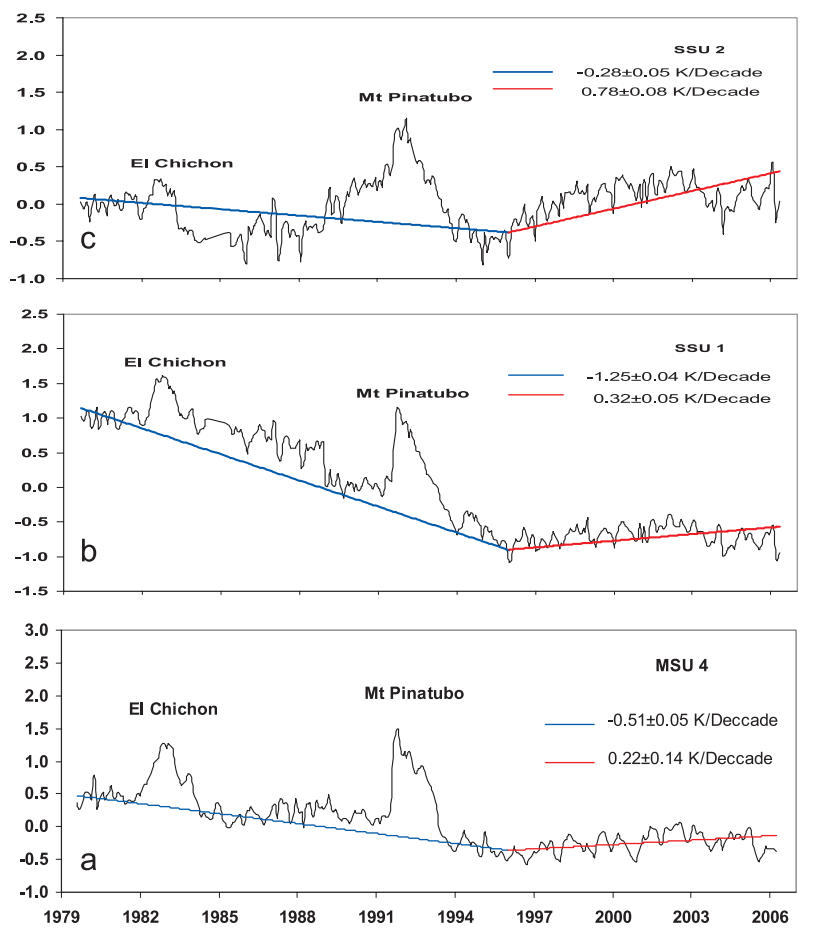

Fig. 4. Time Series of the MSU brightness temperature at channel 4 and the SSU brightness temperatures at channels 1 and 2 . The dual trends are calculated by a least square fitting. The uncertainties in the linear slope or trend are calculated with a 95\% confident level.

stratospheric temperature is correlated with the negative trend in the stratospheric ozone. It is very interesting from Fig. 4 to find the warming trend in the lower and middle stratospheric temperatures after 1996. The positive trend in the stratospheric temperature may suggest a recovery of ozone in the stratosphere.

\section{Discussion}

This study uses a time series of the brightness temperatures from the MSU channel 4 for lower stratospheric temperature, and at the SSU channels 1 and 2 for the middle and upper stratospheric temperature. The cooling trend in the lower stratospheric temperatures before 1996 agrees with previous studies (Ramaswamy et al. 2001; Fu et al. 2004). A slight warming trend in the entire stratosphere since 1996 is found, which may relate to the ozone recovery in the literature (Zanis et al. 2006; Miller et al. 2006). From long-term ozone measurements at Arosa Switzerland Zanis et al. (2006) found a negative trend in stratospheric ozone before 1996 and a positive trend in lower stratospheric ozone between 1996 and 2004. Miller et al. (2006) have utilized a statistical model (Reinsel et al. 2002) to study the ozone trend by using the ozone data from 12 ozonesonde stations in the midlatitude of the Northern Hemisphere. They also found a negative trend before 1996 and a positive trend since 1996 in the lower stratospheric ozone. Their twodimensional regional model results agree with the measurements and show a clear recovery of the stratospheric ozone concentration in the future. This study may provide evidence to the recovery of stratospheric ozone. It should be pointed out that other greenhouse gases such as $\mathrm{CO}_{2}$ and $\mathrm{CH} 4$ are increasing and also affecting stratospheric temperatures (Ramaswamy et al. 2001).

\section{Acknowledgments}

The manuscript contents are solely the opinions of the authors and do not constitute a statement of policy, decision, or position on behalf of NOAA or the US government.

\section{References}

Brindley, H. E., A. J. Geer, and J. E. Harries, 1999: Climate variability and trends in SSU radiances: A comparison of model predictions and satellite observations in the middle stratosphere, J. Climate, 12, 3197-3219.

Cao, C., M. Weinreb, and H. Xu, 2004: Predicting simultaneous nadir overpasses among polar-orbiting meteorological satellites for the intersatellite calibration of radiometers, J. Atmos. Oceanic Technol., 21, 537-542.

Executive Summary, 2006: WMO/UNEP Scientific assessment of ozone depletion.

Fu, Q., C. M. Johanson, S. G. Warren, and D. J. Seidel, 2004: Contribution of stratospheric cooling to satellite-inferred tropospheric temperature trends, Nature, 429, 55-58.

Liu, Q., and F. Weng, 2006: Advanced doubling-adding method for radiative transfer in planetary atmospheres, J. Atmos. Sci., 63, 3459-3465.

Mears, C. A., M. C. Schabel, and F. J. Wentz, 2003: A Reanalysis of the MSU channel 2 tropospheric temperature record, J. Climate, 16, 3650-3664.

Miller, A. J., A. Cai, G. Tiao, D. J. Wuebbles, L. E. Flynn, S. K. Yang, E. C. Weatherhead, V. Fioletov, I. Petropavlovskikh, X. L. Meng, S. Guillas, R. M. Nagatani, and G. C. Reinsel, 2006: Examination of ozonesonde data for trends and trend changes incorporating solar and Arctic oscillation signals, J. Geophys. Res., 111, D13305, doi:10.1029/2005 JD006684.

Newchurch, M. J., L. Bishop, D. Cunnold, L. E. Flynn, S. Godin, S. H. Frith, L. Hood, A. J. Miller, S. Oltmans, W. Randel, G. Reinsel, R. Stolarski, R. Wang, E.-S. Yang, and J. M. Zawodny, 2000: Upper-stratospheric ozone trends 19791998, J. Geophys. Res., 105, 14625-14636.

Ramaswamy, V.. J. Angell, J. Barnett, D. Gaffen, M. Gelman, P. Keckhut, Y. Koshelkov, K. Labitzke, J.-J. R. Lin, A. O'Neill, J. Nash, W. Randel, R. Rood, K. Shine, M. Shiotani, and R. Swinbank, 2001: Stratospheric temperature trends: Observations and model simulations. Rev. Geophys., 39, 71-122.

Reinsel, G. C., E. Weatherhead, G. C. Tiao, A. J. Miller, R. M. Nagatani, D. J. Wuebbles, and L. E. Flynn, 2002: On detection of turnaround and recovery in trend for ozone, $J$. Geophys. Res., 107 (D10), doi:10.1029/2001JD000500.

Seidel, D. J., M. Free, and J. Wang, 2005: Diurnal cycle of upperair temperature estimated from radiosondes, J. Geophys. Res., 110, D09102, doi:10.1029/2004JD005526.

Shepherd, T. G., and A. I. Jonsson, 2007: On the attribution of stratospheric ozone and temperature changes to changes in ozone-depleting substances and well-mixed greenhouse gases, Atmos. Chem. Phys. Discuss, 7, 12327-12347.

Spencer, R. W., and J. R. Christy, 1990: Precise monitoring of global temperature trends from satellites. Science, 247 , 1558-1562.

Vinnikov, K. Y., and N. C. Grody, 2003: Global warming trend of mean tropospheric temperature observed by satellites, Science, 302, 269-272.

Weng, F., 2007: Advances in radiative transfer modeling in support of satellite data assimilation, J. Atmos. Sci., 64, 3799-3807.

Zanis, P., E. Maillard, J. Staehelin, C. Zerefos, E. Kosmidis, K. Tourpali, and I. Wohltmann, 2006: On the turnaround of stratospheric ozone trends deduced from the reevaluated Umkehr record of Arosa, Switzerland, J. Geophys. Res., 111, D22307, doi:10.1029/2005JD006886.

Zou, C., M. D. Goldberg, Z. Cheng, N. C. Grody, J. T. Sullivan, C. Cao, and D. Tarpley, 2006: Recalibration of microwave sounding unit for climate studies using simultaneous nadir overpasses, J. Geophys. Res., 111, D19114, doi: 10.1029/2005JD006798.

Manuscript received 19 February 2009, accepted 26 March 2009 SOLA: http://www.jstage.jst.go.jp/browse/sola/ 